\title{
Individual and area-based indicators of socioeconomic status and childhood asthma
}

\author{
G. Cesaroni*, S. Farchi\#, M. Davoli*, F. Forastiere*, C.A. Perucci*
}

Individual and area-based indicators of socioeconomic status and childhood asthma. G. Cesaroni, S. Farchi, M. Davoli, F. Forastiere, C. A. Perucci. (C)ERS Journals Ltd 2003. ABSTRACT: The current study evaluated the association between individual and areabased indicators of socioeconomic status and the prevalence, severity, and lifetime hospitalisation for asthma in children.

The representative sample of 4,027 children from Rome, aged 6-7 yrs, used for the 1994 ISAAC (International Study on Asthma and Allergies in Childhood) initiative, was selected. Individual and small area indicators of socioeconomic status were used. Individual data on parents' education and on childhood asthma were gathered from selfadministered parental questionnaires. Two small-area indicators (socioeconomic status index (SES) and average income in 1994) were derived using information available at the census tract of residence. Logistic regression models were used to estimate the association of parental education and small area indicators with asthma prevalence, severity, and hospitalisation. Parental smoking was considered in the analysis as a potential confounder.

Prevalence of physician diagnosis of asthma $(11.3 \%)$ increased as father's education decreased. Prevalence of severe asthma (1.6\%) increased as maternal and paternal educational levels decreased. Lifetime hospitalisation for asthma $(2.8 \%)$ was strongly associated with both parental education and small-area indicators of social disadvantage, even when considered simultaneously in the same logistic model.

Socioeconomic conditions are associated with asthma occurrence, its severity, and hospitalisation. The association was stronger for asthma severity and hospitalisation. Individual indicators correlated better with the outcomes than area-based indicators. However, living in an underprivileged area is a strong independent predictor of hospital admission for asthma.

Eur Respir J 2003; 22: 619-624.
*Dept of Epidemiology, Local Health Unit RME and ${ }^{\#}$ Agency for Public Health, Lazio Region, Rome, Italy.

Correspondence: G. Cesaroni

Dipartimento di Epidemiologia

ASL RME

V. di S. Costanza 53

00198 Rome

Italy

Fax: 390683060463

E-mail: cesaroni@asplazio.it

Keywords: Asthma

childhood

socioeconomic status

Received: October 42002

Accepted after revision: April 232003
Several studies in North America have indicated an indirect association between socioeconomic status and asthma prevalence in children [1-3], but in other parts of the world, Europe included, the association is not so clear [4-6]. As has recently been reviewed [4], socioeconomic status can influence asthma occurrence and prognosis. It may contribute as an etiologic factor per se or as a surrogate of environmental risk factors (e.g. passive smoking, indoor mould and dampness), as a component in diagnosis and in labelling the condition, as a factor in the exacerbation of the disease, as a determinant of the quality of care that patients receive, and finally it can also contribute to psychological behaviour, which in turn impacts on the management and prognosis of the condition. These factors can have varying importance in different countries due to cultural differences and organisational structure of healthcare systems.

Socioeconomic disadvantage has been measured in epidemiological studies by individual indicators (education, occupation, house ownership, quality and amenities, income) and by area-based indicators (indices based on an array of social characteristics of residential areas drawn from census data or aggregate income) [7-9]. The association between socioeconomic status and mortality, morbidity and access to health services is well established [10] both when measured at the individual level and when measured with area-based indicators [11, 12]. In Italy, for instance, education and occupational status measured at the individual level have been linked with cancer risk and reduced survival whereas living in underprivileged areas has been associated with mortality [13], survival probability in acquired immune deficiency syndrome (AIDS) [14], and access to coronary artery bypass surgery [15]. The different roles of individual and area-based indicators in measuring health inequalities can differ according to the specific health condition under study, and they can influence disease aetiology as well as the disease management process.

To better elucidate the role played by socioeconomic status on childhood asthma, the present study investigated the extent of the association between individual and area-based indicators of socioeconomic status and the prevalence, severity, and lifetime hospitalisation for asthma among children in Rome.

\section{Methods}

\section{Subjects}

Data were derived from the SIDRIA (Italian Studies on Respiratory Disorders in Childhood and Environment) study, an extension of the ISAAC initiative in Italy (International Study on Asthma and Allergies in Childhood) [16]. In brief, a cross-sectional survey was carried out between October 1994 and March 1995, excluding the main pollen season, in eight 
centres of northern and central Italy using standardised questionnaires. The aim of the survey was to estimate the prevalence of respiratory diseases and allergies in children in Italy and to study the role of several risk factors for asthma, allergic rhinitis, and atopic eczema. The study population consisted of 18,737 children aged 6-7 yrs attending the first and second grades of elementary school. Methods are discussed in more detail elsewhere [5, 6]. Parents answered a self-administered questionnaire on the child's health status and various risk factors, including parental education and smoking. The data used in this analysis are from the subset of children recruited in Rome, who attended the 46 randomly selected schools, totalling 3,917 subjects (response rate $=94 \%$ ).

\section{Socioeconomic indicators}

The individual indicators of socioeconomic status were parental educational level reported on the questionnaire. They were categorised into four groups: primary school or less, junior high school, high school, and university or more.

The area-based indicators were derived from data at the census tract level. Rome has a population of about 2,800,000 inhabitants and is divided into 6,000 census tracts (CT). For this analysis the census tracts with $<50$ residents were combined with the next largest tracts, resulting in a total of 5,736 areas with an average of 480 inhabitants each. The socioeconomic status indicator (SES), that is described in detail elsewhere [13], was developed using 1991 census data on the following characteristics of the census tract of residence: educational level, occupational category, percentage of unemployed men of working age, percentage of one person families, percentage of families with five or more persons, crowding index (persons/room), and percentage of dwellings rented or owned. The value of each variable for each CT was standardised to have a mean of zero and a standard deviation of one, and a factor analysis with varimax rotation on all standardised variables was performed. The sum of the first three factors was used as an overall measure of SES in each CT. The resulting distribution was divided on the basis of the 20th, 50th, and 80th percentiles into four categories of the SES, raging from very well off (level I) to very unprivileged (level IV).

Taxable income earned in 1993 provided by the Italian Tax Register was used to build the census tract income index. The mean per capita income for each census tract was calculated using the population of the tract as the denominator and then the census tracts of Rome were categorised into four levels, using the 20th, 50th and 80th percentile of the distribution. The income index indicated by these levels ranged from the very well off (level I, census tracts with a mean annual income per capita of $€ 12.987$ ) to the poorest (level IV, census tracts with a mean annual income per capita of $€ 3.542$ ).

\section{Outcome measures of asthma}

The prevalence of asthma was measured with the question "Has your child ever been diagnosed with asthma?". Asthma was defined as severe when one of the following conditions had occurred in the last 12 months (ISAAC core questions): $>12$ wheezing attacks, kept awake $\geqslant 1$ nights per week, or speech-limiting wheeze [16]. Lifetime hospitalisation was studied with the question "Has your child ever been admitted to the hospital because of asthma?" The reliability of such definitions has already been reported $[17,18]$.

\section{Data analysis}

A record linkage procedure with the archive of the Municipal Registry Office of Rome was performed to assign

Table 1.-Association between asthma prevalence and indicators of socioeconomic status among children aged 6-7 yrs, Rome

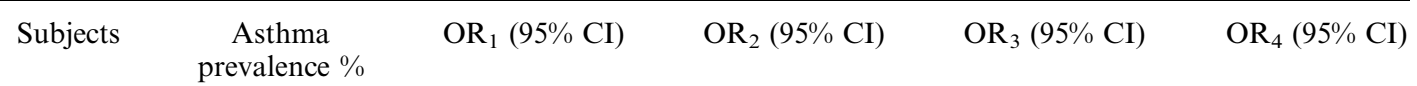

\begin{tabular}{|c|c|c|c|c|c|c|}
\hline \multicolumn{7}{|l|}{ Father's education } \\
\hline University & 690 & 9.8 & 1.00 & 1.00 & 1.00 & 1.00 \\
\hline High school & 1456 & 10.3 & $1.01(0.7-1.4)$ & $0.89(0.6-1.3)$ & $0.92(0.6-1.3)$ & $1.01(0.7-1.4)$ \\
\hline Junior High school & 1293 & 12.0 & $1.23(0.9-1.7)$ & $1.11(0.7-1.7)$ & $1.06(0.7-1.5)$ & $1.21(0.8-1.8)$ \\
\hline Primary school & 364 & 15.4 & $1.68(1.09-2.6)$ & $1.51(0.9-2.6)$ & $1.43(0.9-2.3)$ & $1.64(1.02-2.6)$ \\
\hline $\mathrm{p}$-value for trend & & & 0.010 & 0.053 & 0.095 & 0.022 \\
\hline \multicolumn{7}{|l|}{ Mother's education } \\
\hline University & 573 & 9.5 & 1.00 & 1.00 & & \\
\hline High school & 1588 & 11.4 & $1.21(0.8-1.7)$ & $1.17(0.7-2.1)$ & & \\
\hline Junior High school & 1227 & 11.7 & $1.27(0.9-1.8)$ & $1.13(0.7-1.8)$ & & \\
\hline Primary school & 390 & 12.8 & $1.46(0.9-2.3)$ & $1.18(0.8-1.8)$ & & \\
\hline $\mathrm{p}$-value for trend & & & 0.116 & 0.751 & & \\
\hline \multicolumn{7}{|l|}{ SES index } \\
\hline Highest & 629 & 9.5 & 1.00 & & 1.00 & \\
\hline Intermediate & 829 & 8.6 & $0.95(0.6-1.4)$ & & $0.93(0.6-1.4)$ & \\
\hline Low & 1036 & 13.5 & $1.53(1.09-2.1)$ & & $1.47(1.03-2.1)$ & \\
\hline Lowest & 963 & 12.6 & $1.31(0.9-1.8)$ & & $1.19(0.8-1.7)$ & \\
\hline $\mathrm{p}$-value for trend & & & 0.018 & & 0.130 & \\
\hline \multicolumn{7}{|l|}{ SES index } \\
\hline Highest & 539 & 9.8 & 1.00 & & & 1.00 \\
\hline Intermediate & 896 & 11.1 & $1.11(0.7-1.6)$ & & & $1.04(0.7-1.5)$ \\
\hline Low & 1038 & 10.9 & $1.11(0.8-1.6)$ & & & $1.00(0.7-1.5)$ \\
\hline Lowest & 998 & 12.8 & $1.27(0.9-1.8)$ & & & $1.06(0.7-1.6)$ \\
\hline $\mathrm{p}$-value for trend & & & 0.198 & & & 0.817 \\
\hline
\end{tabular}

$\%$ : crude prevalence; odds ratio $(\mathrm{OR})_{1}$ : adjustment made for parents' smoking habit; $\mathrm{OR}_{2}$ dependent variables: father's education, mother's education, and parents' smoking habit; $\mathrm{OR}_{3}$ dependent variables: father's education, socioeconomic status (SES) index, and parents' smoking habit; $\mathrm{OR}_{4}$ dependent variables: father's education, income area index, and parents' smoking habit; $\mathrm{CI}$ : confidence interval. 
each individual to their census tract of residence and to both area-based socioeconomic indicators at the time of the survey (1994). It was possible to attribute the residence census tract for 3,440 out of 3,917 children. Since both those subjects with and those without area-based indicators did not differ according to parents' level of education, the study population was limited to the 3,440 children with information available on both parental education and area-based indicators.

Spearman's rank order correlation was used to study the correlation between the indicators. Logistic regression models were performed to estimate the independent contribution of the four indicators on prevalence, severity of asthma, and on hospitalisation. Crude odds ratios (OR) were first computed (together with $95 \%$ confidence interval (CI)). Since parental smoking has been shown to be associated with asthma [19] and with socioeconomic status [20], OR were adjusted for parental smoking. Multivariate models were then used to simultaneously estimate the effects of father's education, mother's education, SES index, and income index. Two variables were considered at a time.

\section{Results}

The study population was composed of 2,035 males and 1,882 females. The distribution of parents' educational level and area socioeconomic indicators is shown in the first column of table 1 . Overall asthma prevalence was $11.3 \%$, the prevalence of severe asthma was $1.6 \%$, and any hospitalisation for asthma was reported for $2.7 \%$ of the children.

There was a strong correlation between the two area-based indices (Spearmen's $\mathrm{r}=0.80$ ) and the two individual indices $(r=0.62)$. Although the SES index contains information on the educational level of the people living in the census tract, the correlation between the area-based and the individual indicators was not very high ( $r=0.44$ between SES and father's education, $\mathrm{r}=0.42$ between SES and mother's education, $r=0.48$ and $r=0.47$ between income area index and father's and mother's educational level, respectively).

Parental smoking was not uniformly distributed among different socioeconomic groups. For instance, the percentage of parents who currently smoke went from $51 \%$ in the lowest to $25 \%$ in the highest level of father's education. As expected [19], there was a significant association between current parental smoking and prevalence of asthma, which remained even after adjusting for father's education (OR 1.30, 95\% CI 1.02-1.64). The associations with severe asthma (OR 1.19, 95\% CI 0.65-2.19) and hospitalisation (OR 1.56, 95\% CI 0.96-2.54) were not statistically significant.

Table 1 shows the association of individual and area-based indicators of socioeconomic status with prevalence of asthma $(\%)$. ORs calculated after adjusting for parental smoking $\left(\mathrm{OR}_{1}\right)$ are presented. Physician's diagnosis of asthma increases significantly as father's education decreases, and weaker associations were found with the other indicators, especially the area-based SES index. When father's education was combined with the other indicators (one at a time, $\mathrm{OR}_{2}$ to $\mathrm{OR}_{4}$ ) in the same logistic model, the association remained although it was unstable due to colinearity among the indicators.

Table 2 shows the association between different socioeconomic indicators and the prevalence of severe asthma. High ORs were found for the lowest categories of both parents' level of education when adjustment was made for parental smoking (OR 3.4, 95\% CI 1.2-9.5 for fathers' with a primary school education, and OR 5.3, 95\% CI 1.4-19.5 for mothers with a primary school education). The small area indicators were not associated with asthma severity. When

Table 2. - Association between prevalence of severe asthma and indicators of socioeconomic status among children aged 6-7 yrs, Rome

$\begin{array}{cccc}\begin{array}{c}\text { Severe asthma } \\ \text { prevalence } \%\end{array} & \mathrm{OR}_{1}(95 \% \mathrm{CI}) & \mathrm{OR}_{2}(95 \% \mathrm{CI}) & \mathrm{OR}_{3}(95 \% \mathrm{CI})\end{array}$

\begin{tabular}{|c|c|c|c|c|c|}
\hline \multicolumn{6}{|l|}{ Father's education } \\
\hline University & 1.2 & 1.0 & 1.0 & 1.0 & 1.0 \\
\hline High school & 1.1 & $0.9(0.3-2.3)$ & $0.8(0.2-2.5)$ & $0.8(0.3-2.3)$ & $0.8(0.3-2.4)$ \\
\hline Junior High school & 1.8 & $1.8(0.7-4.6)$ & $1.6(0.5-5.5)$ & $1.7(0.6-4.6)$ & $1.8(0.6-5.0)$ \\
\hline Primary school & 3.5 & $3.4(1.2-9.5)$ & $2.6(0.7-10.3)$ & $3.1(0.98-9.5)$ & $3.1(0.96-10.1)$ \\
\hline $\mathrm{p}$-value for trend & & 0.003 & 0.027 & 0.009 & 0.008 \\
\hline \multicolumn{6}{|l|}{ Mother's education } \\
\hline University & 0.8 & 1.0 & 1.0 & & \\
\hline High school & 1.5 & $2.3(0.7-7.7)$ & $2.0(0.5-8.2)$ & & \\
\hline Junior High school & 1.4 & $2.0(0.6-7.3)$ & $1.4(0.3-6.3)$ & & \\
\hline Primary school & 3.0 & $5.3(1.4-19.5)$ & $2.8(0.6-14.2)$ & & \\
\hline $\mathrm{p}$-value for trend & & 0.020 & 0.447 & & \\
\hline \multicolumn{6}{|l|}{ SES Index } \\
\hline$<20^{\circ}$ percentile & 1.1 & 1.0 & & 1.0 & \\
\hline $20^{\circ}-50^{\circ}$ percentile & 1.8 & $1.5(0.5-3.9)$ & & $1.4(0.5-3.8)$ & \\
\hline $50^{\circ}-80^{\circ}$ percentile & 1.3 & $1.3(0.5-3.4)$ & & $1.0(0.3-2.9)$ & \\
\hline$>80^{\circ}$ percentile & 2.0 & $2.2(0.8-5.5)$ & & $1.5(0.5-4.0)$ & \\
\hline $\mathrm{p}$-value for trend & & 0.120 & & 0.577 & \\
\hline \multicolumn{6}{|l|}{ Income area index } \\
\hline Highest & 1.3 & 1.0 & & & 1.0 \\
\hline Intermediate & 1.8 & $1.4(0.5-4.1)$ & & & $1.3(0.4-3.9)$ \\
\hline Low & 1.2 & $1.3(0.4-3.6)$ & & & $1.0(0.3-3.0)$ \\
\hline Lowest & 2.0 & $2.1(0.8-5.7)$ & & & $1.3(0.4-4.2)$ \\
\hline $\mathrm{p}$-value for trend & & 0.156 & & & 0.734 \\
\hline
\end{tabular}

$\%$ : crude prevalence; odds ratio $(\mathrm{OR})_{1}$ : adjustment made for parents' smoking habit; $\mathrm{OR}_{2}$ dependent variables: father's education, mother's education, and parents' smoking habit; $\mathrm{OR}_{3}$ dependent variables: father's education, socioeconomic status (SES) index, and parents' smoking habit; $\mathrm{OR}_{4}$ dependent variables: father's education, income area index, and parents' smoking habit; CI: confidence interval. 
Table 3. - Association between lifetime hospitalisation for asthma and indicators of socioeconomic status among children aged 6-7 yrs, Rome
Lifetime hospitalisation
$\mathrm{OR}_{1}(95 \% \mathrm{CI})$
$\mathrm{OR}_{2}(95 \% \mathrm{CI})$
$\mathrm{OR}_{3}(95 \% \mathrm{CI})$
$\mathrm{OR}_{4}(95 \% \mathrm{CI})$
for asthma $\%$

\begin{tabular}{|c|c|c|c|c|c|}
\hline \multicolumn{6}{|l|}{ Father's education } \\
\hline University & 0.8 & 1.00 & 1.00 & 1.00 & 1.00 \\
\hline High school & 2.1 & $2.46(0.9-6.5)$ & $2.19(0.7-6.6)$ & $1.86(0.7-5.0)$ & $1.60(0.6-4.4)$ \\
\hline Junior High school & 3.4 & $3.77(1.4-9.7)$ & $3.18(1.0-10.2)$ & $2.40(0.9-6.6)$ & $2.10(0.7-5.9)$ \\
\hline Primary school & 5.4 & $5.61(2.0-15.9)$ & $4.17(1.2-14.9)$ & $3.37(1.1-10.1)$ & $2.96(0.97-9.1)$ \\
\hline $\mathrm{p}$-value for trend & & $\mathrm{p}<0.001$ & 0.018 & 0.020 & 0.030 \\
\hline \multicolumn{6}{|l|}{ Mother's education } \\
\hline University & 1.2 & 1.00 & 1.00 & & \\
\hline High school & 2.1 & $1.54(0.6-3.8)$ & $0.86(0.3-2.4)$ & & \\
\hline Junior High school & 3.4 & $2.65(1.1-6.4)$ & $1.21(0.4-3.6)$ & & \\
\hline Primary school & 5.1 & $3.61(1.4-9.5)$ & $1.50(0.5-5.0)$ & & \\
\hline $\mathrm{p}$-value for trend & & $\mathrm{p}<0.001$ & 0.177 & & \\
\hline \multicolumn{6}{|l|}{ SES index } \\
\hline$<20^{\circ}$ percentile & 1.0 & 1.00 & & 1.00 & \\
\hline $20^{\circ}-50^{\circ}$ percentile & 1.6 & $1.58(0.6-4.3)$ & & $1.38(0.5-3.7)$ & \\
\hline $50^{\circ}-80^{\circ}$ percentile & 3.1 & $3.26(1.3-7.9)$ & & $2.32(0.9-5.8)$ & \\
\hline$>80^{\circ}$ percentile & 4.5 & 4.07 (1.7-9.8) & & $2.80(1.1-7.1)$ & \\
\hline $\mathrm{p}$-value for trend & & $\mathrm{p}<0.001$ & & 0.009 & \\
\hline \multicolumn{6}{|l|}{ Income area index } \\
\hline Highest & 0.8 & 1.00 & & & 1.00 \\
\hline Intermediate & 2.2 & $3.65(1.1-12.5)$ & & & $2.64(0.8-9.4)$ \\
\hline Low & 2.7 & $4.73(1.4-15.8)$ & & & $3.37(0.9-11.9)$ \\
\hline Lowest & 4.4 & $6.84(2.1-22.5)$ & & & $4.46(1.2-15.8)$ \\
\hline $\mathrm{p}$-value for trend & & $\mathrm{p}<0.001$ & & & 0.011 \\
\hline
\end{tabular}

\%: crude prevalence; odds ratio $(\mathrm{OR})_{1}$ : adjustment made for parents' smoking habit; $\mathrm{OR}_{2}$ dependent variables: father's education, mother's education, and parents' smoking habit; $\mathrm{OR}_{3}$ dependent variables: father's education, socioeconomic status (SES) index, and parents' smoking habit; $\mathrm{OR}_{4}$ dependent variables: father's education, income area index, and parents' smoking habit; CI: confidence interval.

father's level of education was included with the other indicators as a dependent variable, only father's educational level remained with a statistically significant trend.

Hospitalisation for asthma was strongly associated (table 3) with all socioeconomic indicators. The OR for fathers with a primary school education versus those with university level was 5.6 (95\% CI 2.0-15.9). When the area-based indicators were considered with father's education, a strong and significant association remained for all the indicators, suggesting that their contribution to the prediction of asthma hospitalisation is independent from each other.

\section{Discussion}

This study indicates an association between low socioeconomic level and asthma in schoolchildren in Rome for both individual and area-based indicators. There is increasing strength in the association between low socioeconomic status and the three outcomes studied; the strongest association is observed for low socioeconomic status and hospitalisation for asthma; the association is weaker for prevalence of severe asthma and weaker still for prevalence of asthma. Unlike other studies [21], but similar to North American reports [1-3], this study shows a possible role of poverty as a contributor to the aetiology of asthma, independent from a known risk factor like parental smoking.

The use of different socioeconomic indicators to assess the extent of the association between socioeconomic status and health outcomes usually depends on the availability of the data. This is the reason why the most common index used in the UK is occupational level while educational level is used in the USA. Studies have been done to determine which is the most adequate indicator of risk, comparing individual indices, individual to area indices, and area indicators [8, 22-24].
Many indicators have been used to study the association between poverty and asthma: educational level [6, 21], income [2], deprivation area indexes and occupational social class [25]. Many studies on socioeconomic status and asthma in childhood provide contradictory results [21], but there are some investigations $[1,25,26]$ that show that severe asthma is more frequent in poorer groups of society. Most studies reported that hospital admission and mortality rates for asthma increase as socioeconomic condition worsens [27].

An important aspect of this study was that diverse socioeconomic indicators were used, measured at two different levels, to investigate the association between socioeconomic status and asthma. The finding that parental education is the strongest predictive indicator (it is associated to all the examined outcomes), in particular father's rather than mother's educational level, suggests that individual indicators are better able to detect socioeconomic differences than geographical ones.

Small area-based socioeconomic indicators in many studies are currently utilised as surrogate or proxy measures of individual socioeconomic position. Generally when random misclassification of individual SES occurs it leads to an underestimation of the effect with the relative risk approaching one. This could explain the weaker association of areabased socioeconomic indicators with outcome measures in this study.

Even though area-based indicators tend to underestimate the effect measure, they must be considered per se a valid measure of socioeconomic status and of its contextual effect [28]; areas of great underprivilege may also be disadvantaged with respect to social organisation, leisure facilities, transportation, pollution, access and quality of healthcare, and all factors that influence health independently of the socioeconomic characteristics of the people living in these areas.

In the present study two area-based indices were used, one 
related to income and one to the socioeconomic characteristics of people living in the area. They both represent the disadvantage of the people living in the area, and are measured at the census tract level. In Rome, this corresponds in most cases to a single block of residence, which assumes a certain homogeneity of living conditions.

As suggested, low social class may be an indicator of several factors relevant to asthma aetiology: indoor air quality, dampness and mould, allergens, exposure to outdoor air pollution. However, the current study observed a stronger association between socioeconomic status and hospitalisation, and severity of asthma than with prevalence. Underrecognition of asthma by parents and underdiagnosis by doctors may explain the weaker association found for asthma prevalence. Parents of children of lower socioeconomic status may report the presence of asthma only when it is associated with more severe symptoms, or when it requires hospitalisation. In other words, there could be an under-reporting of the minor symptoms of asthma, leading to an underestimation of the prevalence of asthma among low socioeconomic status children. This is supported by previous findings that report a strong association between low socioeconomic status and less frequent doctor's diagnosis of asthma among children with wheezing symptoms [29].

The present findings indicate an association of family indicators of socioeconomic status with asthma severity and hospitalisation; moreover, the study found that living in an underprivileged area is an independent predictor of hospital admission.

Living in an area with few social and health services could be a determinant of poor disease management. In this case children with actual asthma suffer more severe consequences of the disease, leading to an increased need for inpatient hospital treatments. More frequent inpatient hospital treatment might occur in case of a limited availability of primary care services, even given the same living conditions, and the same level of disease severity.

Proper management and treatment of asthma should avoid negative outcomes such as severe asthma attacks and hospitalisation. A recent study in Germany [30], however, has underlined several areas of concern regarding childhood asthma management. There was evidence of underuse of antiinflammatory drugs, particularly inhaled steroids. Written management plans and peak flow meters were severely underused for frequent and severe asthma symptoms among underprivileged families. A detailed study on childhood asthma management according to social class in Italy has not been conducted, but, on the basis of the present study's results the current authors can infer that, despite the existence of a national health service providing primary care free of charge, inequality in disease management is present in Rome. To evaluate which aspect of the healthcare system is responsible for this inequality requires further studies.

\section{References}

1. Platt-Mills TAE, Carter MC. Asthma and indoor exposure to allergens. N Engl J Med 1997; 336: 1382-1384.

2. Chen Y, Tang M, Krewski D, et al. Relationship between asthma prevalence and income among canadians. JAMA 2001; 286: 919-920.

3. Von Schlegell A, Grant EN, Weiss KB. The burden of asthma: weighing the community risk against individual risk. Thorax 1999; 54: 471-472.

4. Rona RJ. Asthma and poverty. Thorax 2000; 55: 239-244.

5. Forastiere F, Agabiti N, Corbo GM, et al. Socioeconomic status, number of siblings and respiratory infections in early life as determinants of atopy in children. Epidemiology 1997; 8: 566-570.

6. SIDRIA. Asthma and respiratory symptoms in 6-7 yr old Italian children: gender, latitude, urbanization and socioeconomic factors. Eur Respir J 1997; 10: 1780-1786.

7. Krieger N, Williams DR, Moss NE. Measuring social class in US public health research: concepts, methodologies and guidelines. Annu Rev Public Health 1997; 18: 341-378.

8. Geyer S, Peter R. Income, occupational position, qualification and health inequalities-competing risks? (Comparing indicators of social status). J Epidemiol Community Health 2000; 54: 299-305.

9. Geronimus AT, Bound J. Use of census-based aggregate variables to proxy for socio-economic group: evidence from national samples. Am J Epidemiol 1998; 148: 475-486.

10. Davey-Smith G, Bartley M, Blane D. The black report on socio-economic inequalities in health 10 years on. BMJ 1990; 301: 373-377.

11. Yen I, Kaplan G. Neighborhood social environment and risk of death: multilevel evidence from the Alameda County Study. Am J Epidemiol 1999; 149: 898-907.

12. Diez Roux AV, Stein Merkin S, Arnett D, et al. Neighborhood of residence and incidence of coronary heart disease. N Engl J Med 2001; 345: 99-106.

13. Michelozzi P, Perucci CA, Forastiere F, et al. Inequality in health: socioeconomic differentials in mortality in Rome, 1990-95. J Epidemiol Community Health 1999; 53: 687-693.

14. Rapiti E, Porta D, Forastiere F, et al. Socioeconomic status and survival of persons with AIDS before and after the introduction of Highly Active Antiretroviral Therapy. Lazio AIDS Surveillance Collaborative Group. Epidemiology 2000; 11: 496-501

15. Ancona C, Agabiti N, Forastiere F, et al. Coronary artery bypass graft surgery: socioeconomic inequalities in access and in 30 day mortality. A population-based study in Rome, Italy. J Epidemiol Community Health 2000; 54: 930935.

16. International Study of Asthma and Allergies in Childhood (ISAAC). Worldwide variation in prevalence of symptoms of asthma, allergic rhinoconjunctivitis, and atopic eczema: ISAAC. Lancet 1998; 351: 1225-1232.

17. Jenkins MA, Clarke JR, Carlin JB, et al. Validation of questionnaire and bronchial hyperresponsiveness against respiratory physician assessment in the diagnosis of asthma. Int J Epidemiol 1996; 25: 609-616.

18. Asher MI, Keil U, Anderson HR, et al. International study of asthma and allergies in childhood (ISAAC): rationale and methods. Eur Respir J 1995; 8: 483-491.

19. Agabiti N, Mallone S, Forastiere F, et al. The impact of parental smoking on asthma and wheezing. SIDRIA Collaborative Group. Studi Italiani sui Disturbi Respiratori nell'Infanzia e l'Ambiente. Epidemiology 1999; 10: 692-698.

20. Vannoni F, Bugio A, Quattrociocchi L, et al. Social differences and indicators of perceived health, chronic diseases, disability and lifestyle in the 1994 ISTAT national health interview survey. Epid Prev 1999; 23: 215-229.

21. Mielck A, Reitmeir P, Wjst M. Severity of childhood asthma by socioeconomic status. Int J Epidemiol 1996; 25: 388-393.

22. Diez Roux AV, Kiefe CI, Jacobs DR, et al. Area characteristics and individual-level socio-economic position indicators in three population-based epidemiologic studies. AEP 2001; 11: 395-405.

23. Davey Smith G, Hart C, Hole D, et al. Education and occupational social class: which is the more important indicator of mortality risk? J Epidemiol Community Health 1998; 52: 153-160.

24. Hofer TP, Wolfe RA, Tedeschi PJ, et al. Use of community versus individual socioeconomic data in predicting variation in hospital use. HSR 1998; 33: 143-159.

25. Duran-Tauleria E, Rona RJ. Geographical and socioeconomic variation in the prevalence of asthma symptoms in English and Scottish children. Thorax 1999; 54: 476-481. 
26. Strachan DP, Andreson HR, Limb ES, et al. A national survey of asthma prevalence, severity and treatment in Great Britain. Arch Dis Child 1994; 70: 174-178.

27. Carr W, Zeitel L, Weiss K. Variations in asthma hospitalisations and deaths in New York City. Am J Public Health 1992; 82: 59-65.

28. Hertzman C, Power C, Metthews S, et al. Using an interactive framework of society and lifecourse to explain self-rated health in early adulthood. Soc Sci Med 2001; 53: $1575-1585$.

29. Fuso L, de Rosa M, Corbo GM, et al. Repeatability of the ISAAC video questionnaire and its accuracy against a clinical diagnosis of asthma. Respir Med 2000; 94: 397-403.

30. Maziak W, von Mutius E, Beimfohr C, et al. The management of childhood asthma in the community. Eur Respir $J$ 2002; 20: 1476-1482. 